\title{
Originals
}

\section{Serum lipoproteins and cholesterol metabolism in two hypercholesterolaemic rabbit models}

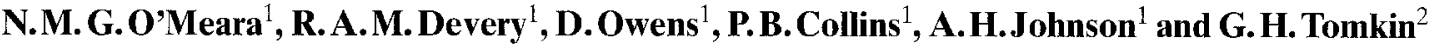 \\ ${ }^{1}$ Department of Biochemistry, Royal College of Surgeons in Ireland, and ${ }^{2}$ Department of Metabolic Medicine, \\ the Adelaide Hospital, Dublin, Ireland
}

Summary. Serum lipoproteins and key hepatic and intestinal enzymes regulating cholesterol synthesis, esterification and catabolism, namely 3-hydroxy-3-methylglutaryl coenzyme A (HMGCoA) reductase, acyl coenzyme A: cholesterol-oacyltransferase (ACAT) and cholesterol $7 \alpha$-hydroxylase respectively, were compared in two hypercholesterolaemic rabbit models - the cholesterol-fed animal and the hypercholesterolaemic diabetic animal. Hypercholesterolaemia in the cholesterol-fed animals was reflected in the VLDL and LDL fractions, whereas VLDL and $\mathrm{HDL}_{2}$ cholesterol levels were elevated in the diabetic animals. The lipoproteins of the cholesterol-fed animals were enriched with cholesterol but the lipoprotein fractions in the diabetic animals were enriched with triacylglycerol. While hepatic HMGCoA reductase activity was significantly reduced in both groups, the activities of hepatic ACAT and cholesterol $7 \alpha$-hydroxylase were significantly increased in the cholesterol-fed animals and significantly reduced in the diabetic animals compared with controls. In the intestine, the activity of HMGCoA reductase was increased and $A C A T$ reduced in the diabetic animals. By contrast, in the cholesterol-fed group, HMGCoA reductase activity was lower and ACAT activity was higher in comparison with the control group. These differences in lipoproteins and cellular cholesterol metabolism between the hypercholesterolaemic rabbit models may explain the differences in susceptibility to atherosclerosis, previously reported in these two animal models.

Key words: Rabbits, diabetes, hypercholesterolaemia, lipoproteins, cholesterol metabolism.
The importance of cholesterol in the pathogenesis of atherosclerosis has been documented by epidemiological [1], biochemical [2] and pathological [3] evidence. The liver and intestine have important roles in the regulation of cholesterol metabolism through their involvement in cholesterol synthesis and esterification, while the liver has an additional role in the catabolism of cholesterol to bile acids. Key enzymes in these processes are 3-hydroxy-3-methylglutaryl coenzyme A reductase (HMGCoA reductase, EC 1.1.1.34), the rate-limiting enzyme of cholesterol biosynthesis [4]; acyl coenzyme A: cholesterol-o-acyltransferase (ACAT, EC 2.3.1.26), the main intracellular enzyme for cholesterol esterification [5] and cholesterol 7 $\alpha$-hydroxylase (EC 1.14.13.7) which catalyses the committed step in bile acid formation [6].

The susceptibility of the rabbit to the development of hypercholesterolaemia and atherosclerosis [7] makes this a suitable species for the study of the role of cholesterol in the pathogenesis of this disease. Increased serum cholesterol levels are found in association with experimentally - induced diabetes mellitus and also following ingestion of cholesterol-supplemented diets.

This study compares serum lipoprotein cholesterol levels and the specific activities of $\mathrm{HMGCoA}$ reductase, ACAT and cholesterol $7 \alpha$-hydroxylase in both the cholesterol-fed and diabetic hypercholesterolaemic rabbit models.

\section{Materials and methods}

\section{Animals}

Male New Zealand White rabbits weighing $3-4 \mathrm{~kg}$ were used in this study and were maintained in a reverse $12 \mathrm{~h}$ light cycle $(03.00-$ 15.00 hours dark, $15.00-03.00$ hours light) and fed Purina rabbit chow and water ad libitum for two weeks prior to commencement of the study. Diabetic animals $(n=6)$ and control animals $(n=6)$ were fed normally throughout the experiments, whereas the cholesterolfed animals $(n=6)$ received Purina rabbit chow supplemented with $2.5 \%$ (weight/volume, w/v) coconut oil and $1 \%$ (w/v) cholesterol for 4 days prior to killing. 


\section{Chemicals}

3-hydroxy-3-methyl $\left(3{ }^{14} \mathrm{C}\right)$-glutaryl CoA $(56.6 \mathrm{mCi} / \mathrm{mmol})$, DL-(2$\left.{ }^{3} \mathrm{H}\right)$-mevalonic acid lactone $(1.28 \mathrm{Ci} / \mathrm{mmol}),\left(1-{ }^{14} \mathrm{C}\right)$-oleic acid $(57.0 \mathrm{mCi} / \mathrm{mmol}),\left(1 \alpha, 2 \alpha(\mathrm{n})^{3} \mathrm{H}\right)$-cholesterol $(40 \mathrm{Ci} / \mathrm{mmol})$ and $\left(3-{ }^{14} \mathrm{C}\right)$-cholesterol $(58.4 \mathrm{mCl} / \mathrm{mmol})$ were obtained from the Radiochemical Centre (Amersham, UK). $\beta$-Nicotinamide adenine dinucleotide phosphate (NADP), $\beta$-nicotinamide adenine dinucleotide phosphate, reduced form (NADPH), glucose 6-phosphate, glucose 6-phosphate dehydrogenase, dithiothreitol (DTT), glutathione, human serum albumin (fatty acid free), oleoyl chloride, nicotinamide, mevalonic acid lactone, coenzyme $\mathrm{A}$, cholesterol and alloxan monohydrate were all obtained from Sigma-London Chemical Co. Ltd. (London, UK). Kieselgel 60 was obtained from Merck (Darmstadt, FRG). Insulin zinc suspension (Ultratard MC) was purchased from Novo Laboratories (Copenhagen, Denmark). Visidex and Multistix reagent strips were obtained from Ames Division, (Miles Laboratories Ltd., Slough, UK).

\section{Induction of diabetes}

Diabetes was induced by intravenous administration of alloxan monohydrate $(140 \mathrm{mg} / \mathrm{kg})$. The alloxan preparation was dissolved in $0-9 \%(\mathrm{w} / \mathrm{v})$ sodium chloride to constitute a $10 \%$ solution immediately prior to injection. The presence of diabetes was confirmed by a Visidex blood sugar reading $>22 \mathrm{mmol} / \mathrm{l}, 48 \mathrm{~h}$ after injection. Throughout the study period, the animals were housed in individual metabolic cages and their diabetic control was monitored by daily urinalysis using Multistix reagent strips. The diabetic animals had significant glycosuria throughout the study but ketonuria was prevented by administering insulin zinc suspension (Ultratard MC) once daily.

Blood was taken for lipoprotein cholesterol estimation and elemental analysis from all three groups of animals following a $16 \mathrm{~h}$ overnight fast. The animals were killed in the middle of the dark period and their livers and intestines were removed and placed on ice.

\section{Preparation of rabbit microsomal pellet}

The livers were minced and then homogenised in 4 volume ice-cold $0.1 \mathrm{~mol} / \mathrm{l}$ potassium phosphate buffer, $\mathrm{pH} 7.4$, containing $1 \mathrm{mmol} / \mathrm{l}$ EDTA and $30 \mathrm{mmol} / \mathrm{l}$ nicotinamide. The homogenate was centrifuged at $800 \mathrm{~g}$ for $10 \mathrm{~min}$ and the resulting supernatant was further centrifuged at $15,000 \mathrm{~g}$ for $20 \mathrm{~min}$. This supernatant was then centrifuged at $104,000 \mathrm{~g}$ for $60 \mathrm{~min}$ to obtain the microsomal pellet. The microsomes were suspended in 0.25 volume $5 \mathrm{mmol} / \mathrm{l}$ imidazole/ $\mathrm{HCl}$ buffer, $\mathrm{pH} 7.4$ containing $0.15 \mathrm{mmol} / 1 \mathrm{NaCl}$ and $5 \mathrm{mmol} / 1$ DTT.

\section{Preparation of rabbit intestinal cells}

Mucosal cell fractions were obtained from rabbit intestine by differential scraping of the mucosa as described by Dietschy and Siperstein [8]. Cells were homogenised in $0.1 \mathrm{~mol} / 1$ potassium phosphate buffer, $\mathrm{pH} 7.4$, containing $1 \mathrm{mmol} / \mathrm{L}$ EDTA and $30 \mathrm{mmol} / 1$ nicotinamide. Due to the relative difficulty in subfractionating intestinal cells compared to liver cells, the activities of HMGCOA reductase and ACAT were measured in the whole homogenate of intestinal cells.

\section{Enzyme assays}

HMGCoA reductase was determined as described by Mitropoulos and Balasubramaniam [9], ACAT by the method of Balasubtamaniam et al. [10] and cholesterol $7 \alpha$-hydroxylase by the method of
Shefer et al. [11]. Prior experimentation with both liver microsomal preparations and intestinal cell whole homogenates from rabbits established optimum assay conditions for the enzymes from both sources with respect to protein concentration and time of incubation [12]. The protein content of the liver and intestinal cell preparations was determined by the method of Lowry et al. [13].

\section{Lipoprotein fractionation}

Plasma lipoproteins were separated by a one step density gradient ultracentrifugation technique as follows [14]. Two ml of serum was brought to a density of $1.225 \mathrm{~g} / \mathrm{ml}$ in the bottom of a modified Beckman ultraclear centrifuge tube (Beckman Instruments Inc., Palo Alto, Calif., USA) by the addition of $770 \mathrm{mg} \mathrm{KBr}$ and $50 \mathrm{mg}$ sucrose. This was then layered with salt solutions having densities of $1.225 \mathrm{~g} / \mathrm{ml}, 1.100 \mathrm{~g} / \mathrm{ml}$ and $1.000 \mathrm{~g} / \mathrm{ml}$. Ultracentrifugation was performed using a Beckman L5-50 ultracentrifuge with an SW $41 \mathrm{Ti}$ swinging-bucket rotor head at $20^{\circ} \mathrm{C}$ at $40,000 \mathrm{rev} / \mathrm{min}$ for $22 \mathrm{~h}$ $\left(26.39 \times 10^{7} \mathrm{~g}_{\text {avg }} \mathrm{min}\right)$. The lipoprotein fractions very low density lipoprotein (VLDL), low density lipoprotein (LDL) and high density lipoprotein subfractions ( $\mathrm{HDL}_{2}$ and $\mathrm{HDL}_{3}$ ) corresponded to the density intervals $<1.006 \mathrm{~g} / \mathrm{ml}, 1.006-1.063 \mathrm{~g} / \mathrm{ml}, 1.063-1.100 \mathrm{~g} / \mathrm{ml}$ and $1.100-1.210 \mathrm{~g} / \mathrm{ml}$, respectively. The density profile in the gradient was checked after ultracentrifugation using a four-digit density meter (Anton Paar, Graz, Austria).

Serum cholesterol levels were assayed using a Boehringer Mannheim $\mathrm{GmbH}$ diagnostic kit [15] and serum triacylglycerol and phospholipid levels were estimated with Biomerieux (Charbonnieres les Bains, France) kits [16]. The protein content of the lipoprotein fractions was measured by a modification [17] of the procedure of Lowry et al. [13].

\section{Statistical analysis}

Statistical analysis of changes in the activities of HMGCoA reductase, ACAT and cholesterol $7 \alpha$-hydroxylase, between the various groups of animals was performed using the Student's unpaired $t$-test (two-tailed). As the serum lipid levels in the cholesterol-fed and diabetic rabbits were not normally distributed, the Wilcoxon test

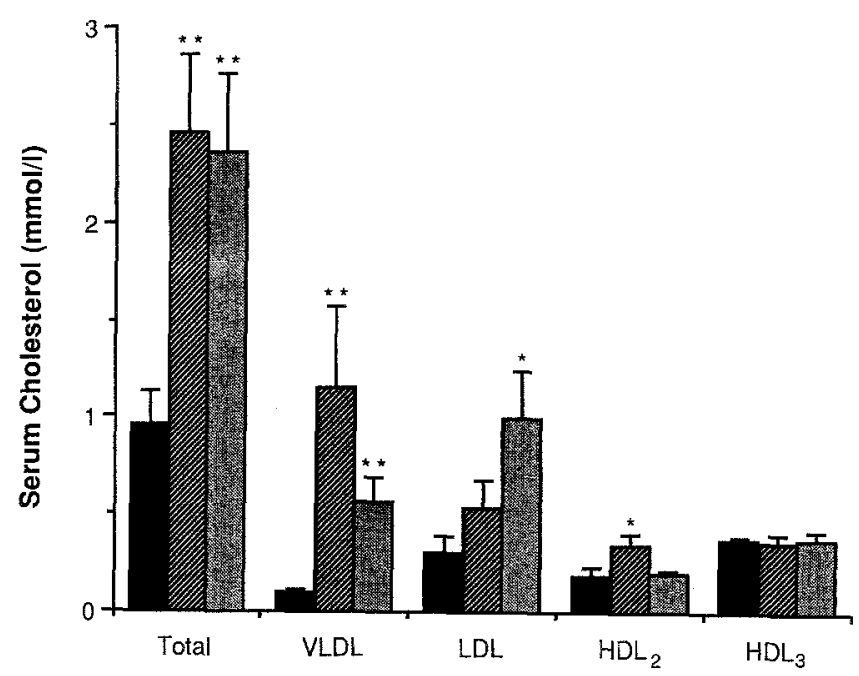

Fig. 1. Serum cholesterol levels and distribution in hypercholesterolaemic rabbits. The individual lipoprotein fractions were isolated ultracentrifugally and the cholesterol content of each was measured enzymatically. Control animals ( $n=6$, black bars); diabetic animals ( $n=6$, striped bars); cholesterol-fed animals ( $n=6$, stippled bars). Results are expressed as mean \pm SEM. $* p<0.05$ different from control animals; ${ }^{* * *} p<0.01$ different from control animals 
Table 1. Effect of cholesterol feeding and diabetes on the elemental composition of the lipoprotein subfractions in the rabbit

\begin{tabular}{lccc}
\hline & $\begin{array}{c}\text { Control } \\
\text { animals } \\
(n=6)\end{array}$ & $\begin{array}{l}\text { Diabetic } \\
\text { animals } \\
(n=6)\end{array}$ & $\begin{array}{c}\text { Cholesterol- } \\
\text { fed animals } \\
(n=6)\end{array}$ \\
\hline VLDL \% & $40.7 \pm 4.3$ & $48.6 \pm 2.8$ & $13.0 \pm 4.7^{\mathrm{c}}$ \\
$\quad$ Triacylglycerol & $16.5 \pm 3.3$ & $10.5 \pm 1.4$ & $45.2 \pm 5.1^{\mathrm{c}}$ \\
Cholesterol & $18.4 \pm 1.7$ & $15.1 \pm 1.7$ & $19.8 \pm 1.3$ \\
Phospholipid & $24.3 \pm 1.4$ & $25.8 \pm 2.8$ & $22.0 \pm 3.5$ \\
Protein & & & \\
LDL\% & $12.1 \pm 1.7$ & $23.7 \pm 3.2^{\mathrm{b}}$ & $2.2 \pm 0.4^{\mathrm{c}}$ \\
Triacylglycerol & $22.4 \pm 3.4$ & $14.6 \pm 2.7$ & $38.1 \pm 1.8^{\mathrm{c}}$ \\
Cholesterol & $27.0 \pm 1.2$ & $23.9 \pm 2.0$ & $23.6 \pm 0.8$ \\
Phospholipid & $38.5 \pm 3.3$ & $37.9 \pm 3.3$ & $36.1 \pm 1.0$ \\
Protein & & & \\
HDL $\%$ & $6.9 \pm 0.9$ & $15.5 \pm 2.3^{\mathrm{b}}$ & $2.4 \pm 0.6^{\mathrm{a}}$ \\
Triacylglycerol & $15.4 \pm 1.5$ & $12.0 \pm 2.0$ & $17.5 \pm 0.8$ \\
Cholesterol & $35.4 \pm 2.8$ & $35.8 \pm 2.0$ & $26.2 \pm 2.1$ \\
Phospholipid & $42.3 \pm 2.0$ & $36.7 \pm 2.8$ & $53.9 \pm 2.4^{\mathrm{a}}$ \\
Protein & & & \\
HDL \% & $9.2 \pm 1.1$ & $11.2 \pm 1.6$ & $2.6 \pm 0.5^{\mathrm{c}}$ \\
Triacylglycerol & $9.0 \pm 0.8$ & $9.0 \pm 1.0$ & $8.9 \pm 1.7$ \\
Cholesterol & $18.9 \pm 3.9$ & $20.9 \pm 0.3$ & $16.6 \pm 1.7$ \\
Phospholipid & $62.9 \pm 3.5$ & $60.9 \pm 0.9$ & $71.9 \pm 1.3^{\mathrm{a}}$ \\
\hline Protein & & & \\
\hline
\end{tabular}

The percentage composition was calculated by measuring the triglyceride, cholesterol, phospholipid and protein concentration in each lipoprotein fraction from which the total mass of each fraction was calculated. Each component was then expressed as a percentage of the total particle mass. Results expressed as means \pm SEM.

a $p<0.05$ different from control animals;

${ }^{b} p<0.01$ different from control animals;

${ }^{c} p<0.001$ different from control animals

(two-tailed) was used in the analysis of this data. The results are expressed as mean \pm SEM.

\section{Results}

Figure 1 outlines the serum cholesterol concentrations in all three groups. The degree of hypercholesterolaemia in the cholesterol-fed group and the diabetic group was comparable $(2.35 \pm 0.44$ vs $2.45 \pm 0.41 \mathrm{mmol} / \mathrm{l})$. These levels were significantly higher $(p<0.01)$ than the cholesterol levels in the control rabbits $(1.02 \pm 0.20 \mathrm{mmol} / 1)$. While the hypercholesterolaemia in the cholesterol-fed animals was reflected mainly in the VLDL $(p<0.01)$ and LDL $(p<0.05)$ fractions, the elevated serum cholesterol levels in the diabetic group were reflected principally in the VLDL $(p<0.01)$ and $\mathrm{HDL}_{2}(p<0.05)$ fractions. Total triacylglycerol levels in serum were reduced $(p<0.01)$ in the cholesterol-fed animals $(0.222 \pm 0.028 \mathrm{mmol} / \mathrm{l})$ and increased $(p<0.01)$ in the diabetic animals $(4.05 \pm 1.30 \mathrm{mmol} / \mathrm{l})$ compared to the control animals $(0.59 \pm 0.05 \mathrm{mmol} / 1)$. Serum phospholipid levels were significantly higher $(p<0.01)$ in the diabetic animals $(2.69 \pm 0.37 \mathrm{mmol} / \mathrm{l})$ in comparison with the control group $(1.16 \pm 0.19 \mathrm{mmol} / \mathrm{l})$. The increase in serum phospholipid levels in the cholesterol-fed animals $(1.28 \pm 0.11 \mathrm{mmol} / \mathrm{l})$ did not attain statistical significance.

Table 1 demonstrates the elemental composition of the lipoprotein fractions of the three animal groups. In comparison with the control animals, the VLDL and LDL particles in the cholesterol-fed animals were enriched with cholesterol while the proportion of triacylglycerol in these particles was reduced. However, in the diabetic animals, all lipoprotein particles were enriched with triacylglycerol. This was associated with a generalised reduction in the proportion of cholesterol in each fraction and a reduction in the proportion of protein in the $\mathrm{HDL}_{2}$ and $\mathrm{HDL}_{3}$ fractions.

The specific activities of HMGCoA reductase, ACAT and cholesterol $7 \alpha$-hydroxylase are outlined in Figure 2. HMGCoA reductase activity was significantly reduced in both the cholesterol-fed $(p<0.001)$ and diabetic $(p<0.025)$ rabbits. The specific activity of hepatic ACAT was higher $(p<0.001)$ in the cholesterol-fed animals and lower $(p<0.001)$ in the diabetic animals in comparison with the controls. Similarly, the specific activity of cholesterol $7 \alpha$-hydroxylase was increased $(p<0.001)$ in the cholesterol-fed group and reduced $(p<0.01)$ in the diabetic group.

Figure 3 demonstrates the specific activities of HMGCOA reductase and ACAT in the intestines of the three animal groups. HMGCoA reductase activity was higher $(p<0.005)$ in the diabetic animals and lower $(p<0.01)$ in the cholesterol-fed animals compared with controls. By contrast, the specific activity of ACAT was reduced $(p<0.001)$ in the diabetic group and increased $(p<0.001)$ in the cholesterol-fed group in comparison with the normocholesterolaemic control animals.
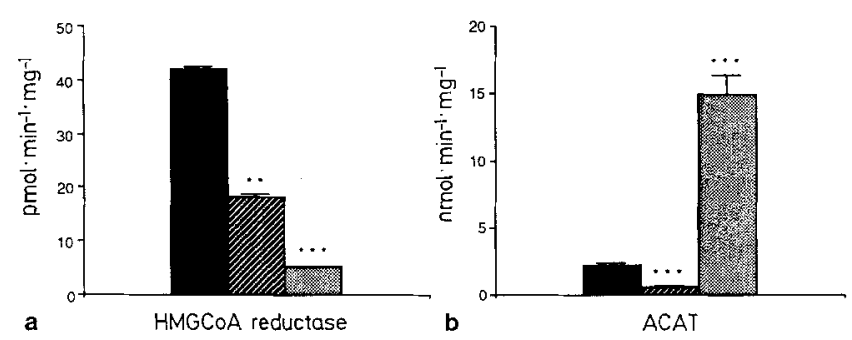

Fig. 2 a-c. Effect of diabetes and cholesterol feeding on the specific activity of hepatic cholesterol metabolising enzymes. Each enzyme activity was measured in liver microsomal pellets. a HMGCoA reductase, b (cholesterol-o-acyltransferase) ACAT, c cholesterol $7 \alpha$ hydroxylase. Control animals ( $n=6$, black bars); diabetic animals

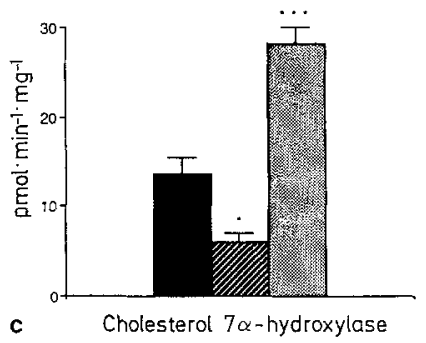

( $n=6$, striped bars); cholesterol-fed animals ( $n=6$, stippled bars). Results are expressed as mean \pm SEM. ${ }^{*} p<0.01$ different from control animals; $* * p<0.025$ different from control animals; *** $p<0.001$ different from control animals 

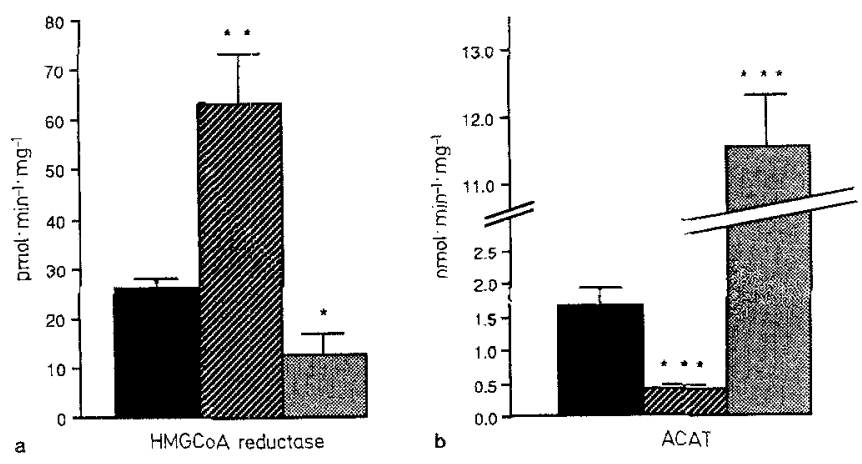

Fig. 3 a, b. Effect of diabetes and cholesterol feeding on the specific activity of intestinal cholesterol metabolising enzymes. Both activities were measured in mucosal cell whole homogenates. a HMGCoA reductase, b (cholesterol-o-acyltransferase) ACAT. Control animals ( $n=6$, black bars); diabetic animals ( $n=6$, striped bars); cholesterol-fed animals ( $n=6$, stippled bars). Results are expressed as mean \pm SEM. $* p<0.01$ different from control animals; $* *{ }^{*} p<0.005$ different from control animals; $* * * p<0.001$ different from control animals

\section{Discussion}

The cholesterol-fed rabbits responded to the exogenously induced hypercholesterolaemia by suppressing endogenous hepatic and intestinal cholesterol synthesis, increasing cholesterol esterification in the liver and the intestine and by increasing cholesterol excretion in bile. The effects of cholesterol feeding on cholesterol metabolising enzymes in the rabbit are supportive of earlier findings in this laboratory [18] and elsewhere in rabbits [19] guinea pigs [20] and hamsters [21]. This reduced synthesis and increased utilisation of cholesterol in the cholesterol-fed animal is therefore an adaptive response to the increased availability of cholesterol [22].

The hypercholesterolaemia in the diabetic rabbits was, by contrast, endogenously induced. While the aetiology of diabetic hypercholesterolaemia has not been clearly defined, studies in many insulinopoenic animal models suggest that increased intestinal cholesterologenesis is a contributory factor [23-25]. The elevated intestinal HMGCoA reductase activity in the alloxan-treated rabbits in this study is therefore consistent with this theory and the diabetic animal, like the cholesterol-fed animal, responded to the resultant increased availability of cholesterol by suppressing hepatic cholesterol synthesis. However, in contrast to the cholesterol-fed animals, the activity of ACAT and cholesterol $7 \alpha$-hydroxylase was reduced in the diabetic animals. This suggests that decreased hepatic and intestinal cholesterol esterification and a reduction in the rate of catabolism of cholesterol to bile acids, might be contributing factors in the pathogenesis of hypercholesterolaemia in the diabetic rabbit. Such a situation could arise if insulin regulated the activity of these enzymes in the rabbit in vivo. However, previous in vitro studies in the rat have not demonstrated such an effect $[26,27]$.

In both diabetic and cholesterol-fed groups, the increased cholesterol appears to have been utilised for lipoprotein formation. While the VLDL particles in the cholesterol-fed animals were rich in cholesterol, the VLDL fractions in the diabetic animals were enriched with tri- acylglycerol. Thus, the high VLDL cholesterol levels in the diabetic animals reflected the presence of a greater number of VLDL particles, although the quantity of cholesterol in each particle was reduced. By contrast, the elevated VLDL cholesterol levels in the cholesterol-fed animals reflected primarily the enrichment of each VLDL particle with cholesterol. While the ratio of free cholesterol to cholesteryl ester in the VLDL fractions was not quantified, previous studies have shown that these particles are rich in cholesteryl-ester in cholesterol-fed animals $[28,29]$. These findings would be consistent with the increased ACAT activity observed in the cholesterol-fed rabbits in this study.

In the cholesterol-fed animals, the elevated VLDL cholesterol levels were accompanied by similar increases in LDL cholesterol. While some VLDL is converted to LDL in the normal rabbit $[30,31]$, previous kinetic experiments have shown that VLDL catabolism is reduced in the cholesterol-fed rabbit [32]. Since it has been demonstrated that cholesterol feeding in the rabbit causes down regulation of LDL receptors [33], it is likely that the elevated LDL cholesterol levels in the cholesterol-fed animals resulted from impaired LDL catabolism rather than increased VLDL turnover.

In the diabetic animals, the increased VLDL cholesterol levels were accompanied principally by changes in $\mathrm{HDL}_{2}$ cholesterol while LDL cholesterol levels were only slightly raised. The small increase in LDL cholesterol occurred in a situation where the proportion of cholesterol in each particle was reduced. This suggests that LDL particle number is increased in the diabetic animals. As these LDL particles are enriched with triacylglycerol, it is likely that the increased number of LDL particles resulted from increased VLDL catabolism. Increased hydrolysis of VLDL in the diabetic rabbit could also account for the increased $\mathrm{HDL}_{2}$ cholesterol levels observed, since during VLDL catabolism in the rabbit, apoprotein transfer from VLDL to HDL has been observed [34].

In conclusion, this study highlights the contrasting changes in cellular and lipoprotein cholesterol metabolism in two different hypercholesterolaemic models. Some investigations of cholesterol metabolism in diabetes have been performed in animals consuming diets rich in cholesterol [35, 36]. The data reported here emphasise the hazards of such an approach since many of the experimental findings may be dietary related and cannot therefore be attributed specifically to diabetes. It has previously been shown that the incidence of atherosclerosis in the diabetic hypercholesterolaemic rabbit model is reduced in contrast to its cholesterol-fed counterpart [37-39]. The differences in hepatic and intestinal cholesterol metabolism in serum lipoproteins between these two models may in part explain this observation.

\section{References}

1. Kannel WB, Castelli WP, Gordon T (1979) Cholesterol in the prediction of atherosclerotic disease. Rev Ann Intern Med 90: 85-91 
2. Ross R, Harker L (1976) Hyperlipidaemia and atherosclerosis. Science 193: 1094-1100

3. Insull W Jr, Bartsch GE (1966) Cholesterol, triglyceride and phospholipid content of intima, media and atherosclerotic fatty streak in human thoracic aorta. J Clin Invest 45: 513-523

4. Rodwell VW, Nordstrom JL, Mitschelen JJ (1976) Regulation of HMGCoA reductase. Adv Lipid Res 14: 1-74

5. Goodman DS, Deykin D, Shiratori T (1964) The formation of cholesterol esters with rat liver enzymes. J Biol Chem 239: 13351345

6. Shefer S, Hauser S, Bekersky I, Mosbach EH (1970) Biochemical site of regulation of bile acid biosynthesis in the rat. J Lipid Res 11: 404-411

7. Vesselinovitch D, Wissler RW (1977) Comparison of primates and rabbits as animal models in experimental atherosclerosis. Adv Exp Med Biol 82: 614-622

8. Dietscy JM, Siperstein MD (1965) Cholesterol synthesis by the gastrointestinal tract: localization and mechanisms of control. J Clin Invest 44: 1311-1327

9. Mitropoulos KA, Balasubramaniam S (1976) The role of glucocorticoids in the regulation of the diurnal rhythm of hepatic $\beta$-hydroxy- $\beta$-methylglutaryl coenzyme $A$ reductase and cholesterol $7 \alpha$-hydroxylase. Biochem J 160: 49-55

10. Balasubramaniam S, Mitropoulos KA, Venkatesan S (1978) Rat liver acyl-CoA: cholesterol acyltransferase. Eur J Biochem 90: 377-383

11. Shefer S, Cheng FW, Hauser S, Batta AK, Salen G (1981) Regulation of bile acid synthesis. Measurement of cholesterol $7 \alpha-$ hydroxylase activity in rat liver microsomal preparations in the $a b$ sence of endogenous cholesterol. J Lipid Res 22: 532-536

12. Devery RAM, O'Meara N, Collins PB, Johnson AH, Scott L, Tomkin GH (1987) A comparative study of the rate-limiting enzymes of cholesterol synthesis, esterification and catabolism in the rat and rabbit. Comp Biochem Physiol 87B: 697-702

13. Lowry OH, Rossbrough NJ, Farr AL, Randall RJ (1951) Protein measurement with the Folin phenol reagent. J Biol Chem 193: 265-275

14. O'Donnell L, Owens D, McGee C, Devery R, Hession P, Collins P, Johnson A, Tomkin G (1988) Effects of catecholamines on serum lipoproteins in normally-fed and cholesterol-fed rabbits. Metabolism 37: 910-915

15. Roschlau P, Bernt E, Gruber W (1974) Enzymatic determination of total cholesterol in serum using peroxidase as indicating enzyme. J Clin Chem Clin Biochem 12:226

16. Takayama J, Itoh S, Nagasaki T, Tanimizu I (1977) A new enzymatic method for determination of serum choline-containing phospholipids. Clin Chim Acta 79: 93-98

17. Markwell MAK, Haas SM, Bieber LL, Tolbert NE (1978) A modification of the Lowry procedure to simplify protein determination in membrane and lipoprotein samples. Anal Biochem 87: 206-210

18. Devery R, O'Donnell L, Tomkin GH (1986) Effect of catecholamines on the hepatic rate-limiting enzymes of cholesterol metabolism in normally-fed and cholesterol-fed rabbits. Biochem Biophys Acta 887: 173-181

19. Stange EF, Alavi M, Schneider A, Ditschuneit M, Poley JR (1981) Influence of dietary cholesterol, saturated and unsaturated lipid on 3-hydroxy-3-methylglutaryl CoA reductase activity in rabbit intestine and liver. J Lipid Res 22: 47-56

20. Turley SD, West CE (1976) Effect of cholesterol and cholestyramine feeding and of fasting on sterol synthesis in the liver, ileum and lung of the guinea pig. Lipids 2: 571-577

21. Jackson B, Gee AN, Martinez-Ceyvela M, Suckling KE (1990) The effects of feeding a saturated fat-rich diet on enzymes of cholesterol metabolism in the liver, intestine and aorta of the hamster. Biochem Biophys Acta 1048: 21-28

22. Mitropoulos KA, Balsaubramaniam S, Vankatesan S, Reeves BEA (1978) On the mechanism for the regulation of 3-hydroxy3-methylglutaryl coenzyme A reductase, of cholesterol $7 \alpha$-hydroxylase and of acyl-coenzyme A: cholesterol acyltransferase by free cholesterol. Biochim Biophys Acta 530:99-111
23. Nakayama H, Nakagawa S (1977) Influence of streptozotocin diabetes on intestinal 3-hydroxy-3-methylglutaryl coenzyme A reductase activity in the rat. Diabetes 26: 439-444

24. Young NL, Saudek CD, Crawford SA (1982) Total hydroxymethylglutaryl CoA reductase activity in the small intestine and liver of insulin deficient rats. J Lipid Res 23: 266-275

25. Feingold KR, Lear SR, Moser AH (1984) De novo cholesterol synthesis in three different animal models of diabetes. Diabetologia 26: 234-239

26. Subbiah MTR, Yunker RL (1984) Evidence for the presence of non-lipoprotein factors in diabetic serum capable of stimulating rat hepatic cholesterol $7 \alpha$-hydroxylase in vitro. Biochem Biophys Res Commun 121:743-748

27. Devery R, Tomkin GH (1986) The effect of insulin and catecholamines on the activities of 3-hydroxy-3-methylglutaryl coenzyme A reductase and acyl-coenzyme A: cholesterol-Oacyltransferase in isolated rat hepatocytes. Diabetologia 29: 122124

28. Rodriguez JL, Chiselli CC, Torreggiani D, Sirtori CP (1976) Very low density lipoproteins in normal and cholesterol-fed rabbits: lipid and protein composition and metabolism. Part 1: chemical composition of very low density lipoproteins in rabbits. Atherosclerosis 23: 73-83

29. Roth RI, Gaubatz JW, Gotto AM Jr, Patsch JR (1983) Effect of cholesterol feeding on the distribution of plasma lipoproteins and on the metabolism of apolipoprotein B in the rabbit. J Lipid Res 24: 1-11

30. Ghiselli G (1982) Evidence that two synthetic pathways contribute to the apolipoprotein B pool of the low density lipoprotein fraction of rabbit plasma. Biochim Biophys Acta 711: 311-315

31. Kita T, Brown MS, Bilheimer DW, Goldstein JL (1982) Delayed clearance of very low density and intermediate density lipoproteins with enhanced conversion to low density lipoprotein in WHHL rabbits. Proc Natl Acad Sci USA 79: 5693-5697

32. Rodriguez JL, Catapano A, Ghiselli GC, Sirtori CR (1976) Very low density lipoproteins in normal and cholesterol fed rabbits: lipid and protein composition and metabolism. Part 2: metabolism of very low density lipoproteins in rabbits. Atherosclerosis 23: 85-96

33. Kovanen PT, Brown MS, Basu SK, Bilheimer DW, Golstein JL (1981) Saturation and suppression of hepatic lipoprotein receptors: a mechanism for the hypercholesterolaemia of cholesterolfed rabbits. Proc Natl Acad Sci USA 78: 1396-1400

34. Kushwaha RS, Hazzard WR (1978) Catabolism of very low density lipoproteins in the rabbit. Effect of changing composition and pool size. Biochim Biophys Acta 528: 176-189

35. Arbeeny CM, Edelstein D, Freedman SR, Eder HA (1980) Serum lipoproteins of diabetic rats fed a high cholesterol diet. Diabetes 29: 774-777

36. Van Sickel WA, Brecher P, Aspen A, Chobanian AV (1985) Effect of fasting on the composition of plasma lipoproteins in cholesterol-fed diabetic rabbits. J Lipid Res 26: 442-450

37. Duff GL, McMillan GC (1949) The effect of alloxan diabetes on experimental cholesterol atherosclerosis in the rabbit. J Exp Med 89: 611-639

38. Brecher P, Chobanian AV, Small DM, Van Sickle W, Zeroyak A, Lazzari A, Baler J (1983) Relationship of an abnormal plasma lipoprotein to protection from atherosclerosis in the cholesterolfed diabetic rabbit. J Clin Invest 72: 1553-1562

39. Miller NA, Wilson RB (1984) Atherosclerosis and myocardial ischaemic lesions in alloxan diabetic rabbits fed a low cholesterol diet. Atherosclerosis 4: 586-591

Received: 12 July 1990

and in revised form: 2 October 1990

Dr. N.M.G. O'Meara

Department of Biochemistry

Royal College of Surgeons in Ireland

Dublin 2

Ireland 